\title{
Landslide prediction using aging stability theory of creep
}

\author{
Jingde Liu \\ Shanghai Shen Yuan Geotechnical Engineering Co. Ltd., Shanghai 200040, China \\ liu-jd03@126.com
}

Keywords: landslide, aging stability theory, creep, aging conjugate point, viscoelastic lag coefficient Abstract. The aging stability theory of creep aims to describe simultaneously the steady-state creep and accelerated creep of rock and soil by coupling Kelvin model and Saito model. In the project of Mount Niu-shou tourist district, several landslides have been successfully predicted and forecasted by fitting the monitoring data in the framework of the aging stability theory of creep. The predicted destabilization time $t_{\mathrm{f}}$ is close to and earlier than the real time of landslide, and thus landslide forecast could be made in time to reduce casualties and property loss.

\section{Introduction}

Landslide is one of the worst natural disasters for human beings and often leads to severe casualties and property loss. Correct prediction and forecast of landslide is important to reduce such casualties and property loss. The prediction and forecast of landslide includes the forecast of destabilization time of slope and the prediction of slope deformation tendency. There are many methods to forecast the destabilization time of slope, such as Saito model [1], Voight model [2] and synergetic prediction model [3].

It has been found that the slope deformation generally consists of initial deformation stage, steady-state deformation stage and accelerated deformation stage before landslide occurs. The severe accelerated deformation is often regarded as the most significant symptom of slope failure. Hence, the monitoring data of slope deformation - time become the main and primary basis to make landslide prediction and forecast. The key problems to forecast landslide using slope deformation monitoring data are to correctly determine the beginning of the accelerated deformation of slope and to predict the destabilization time using the accelerated deformation data. By coupling the Kelvin model [4] and Saito model [1], Yang [5] successfully solved the above two problems and established the aging stability theory of creep to perform landslide prediction and forecast based on the slope deformation.

The aging stability theory of creep for rock and soil has been adopted to predict the slope failure time in the project of Mount Niu-shou tourist district and successfully forecast most of the landslide. This paper aims to introduce the application of the aging stability theory of creep in landslide prediction and forecast in this project by taking GPS-17 monitoring site as an example.

\section{Aging stability theory of creep}

It is accepted that rock and soil tend to creep under constant stress and the creep curve consists mainly of a decaying creep stage, a steady state creep stage and an accelerated creep stage. According to the aging stability theory of creep, the mechanical characteristics of rock or soil at steady-state creep stage can be described by the Kelvin model [4] expressed as

$$
\frac{\mathrm{d}^{2} y}{\mathrm{~d} t^{2}}+\xi \frac{\mathrm{d} y}{\mathrm{~d} t}=\frac{\mathrm{d}^{2} y}{\mathrm{~d} t^{2}}+\frac{E}{\eta} \frac{\mathrm{d} y}{\mathrm{~d} t}=0
$$

where $E$ is the elastic modulus; $\eta$ is the viscosity coefficient; $\xi$ is the viscoelastic lag coefficient. The mechanical characteristics of rock or soil at accelerated creep stage can be described by the Saito model [1] expressed as

$$
\frac{\mathrm{d}^{2} y}{\mathrm{~d} t^{2}}-A\left(\frac{\mathrm{d} y}{\mathrm{~d} t}\right)^{\alpha}=0
$$


where $A$ is the buckling strength coefficient and $\alpha$ is the aging index of instability.

In the framework of the aging stability theory of creep [5], it is assumed that Eq. (1) and Eq. (2) can be coupled at the aging conjugate point $t_{\mathrm{p}}$ of the creep curve of rock or soil if the creep failure occurs. The aging conjugate point $t_{\mathrm{p}}$ is the time when the creep curve gets into the accelerated creep stage from the steady-state creep stage. In addition, it is also assumed that the destabilization time $t_{\mathrm{f}}$ caused by severe sliding can be predicted using the Eq. (2). It is thought that the creep failure of rock or soil occurs at the destabilization time $t_{\mathrm{f}}$. Following the continuity of deformation and deformation rate of the creep curve, the aging conjugate point $t_{\mathrm{p}}$ and the destabilization time $t_{\mathrm{f}}$ can be obtained by fitting out the monitoring data.

To verify whether or not the obtained $t_{\mathrm{p}}$ is the real aging conjugate that the creep curve reaches the accelerated creep stage, a variable $v_{e}[5]$ is defined as

$$
v_{e}=\frac{v_{0}}{\xi y_{p}}
$$

where $v_{0}$ is the initial creep deformation rate of steady-state creep stage, $y_{\mathrm{p}}$ is the deformation at the time $t_{\mathrm{p}}$. If $v_{e}=1.0$, the rock or soil will be always stable. If $v_{e}>1.0$, however, the rock or soil reaches the accelerated creep stage from the steady-state creep stage and the creep failure will occur at certain time. Hence, Variable $v_{e}$ can be regarded as the criterion index of rock or soil reaching accelerated creep stage from steady-state creep stage.

\section{Landslide prediction in project of Mount Niu-shou tourist district}

Project outline. The Project of Mount Niu-shou tourist district is an important resort of Zen culture planned by Nanjing Municipal government. The main building of the tourist district is Fo-ding Temple, which is located in an abandoned mine pit. The pile foundation and the building base of the Fo-ding Temple generally lie on the slope of the abandoned pit with a level difference as high as $141 \mathrm{~m}$. Moreover, the pit slope is highly fractured and contains lots of rock faults, joints and cracks.

To ensure the safety of the Fo-ding Temple during operation periods, synthetically measures such as anchor chains, anchor injection and high strength anchor are jointly adopted to reinforce the pit slope. Due to the high level difference of the highly fractured pit slope, it is also important to take measures to avoid various risks during the slope reinforcement construction. Hence, field monitoring and informative construction method were used.

Based on the monitoring data of slope deformation, the aging stability theory of creep was adopted to predict the landslide. If necessary, warnings and forecasts or landslide would be made and emergency actions would be taken to reduce casualties and property damage. Most of slope landslides have been successfully forecasted during the construction of the slope reinforcement. The monitoring site GPS-17 as illustrated in Fig. 1 will be used to introduce landslide prediction using the aging stability theory of creep in the construction of Mount Niu-shou tourist district.

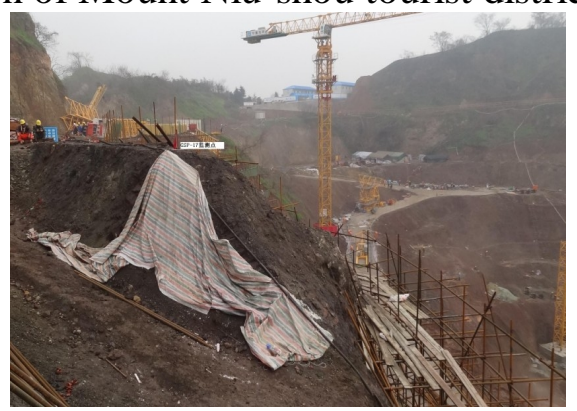

Fig. 1 GPS-17 monitoring site

Landslide prediction of GPS-17 monitoring site. The slope deformation at GPS-17 site has been monitored every three days since January $9^{\text {th }}, 2013$. The slope surface around GPS-17 site was found slightly cracking on March $13^{\text {th }}, 2013$ and close attention was then paid to the prediction of landslide that could occurred around this site. 
On March $19^{\text {th }}$, the slope crack expanded significantly and extended laterally due to the rainfall on $17^{\text {th }}$. Fig. 2 shows the monitoring data from $1^{\text {st }}$ to $19^{\text {th }}$ of the slope deformation at GPS-17 site. It can be seen that the slope deformation increased notably from $16^{\text {th }}$ to $19^{\text {th }}$, which was also caused by the rainfall. Based on the aging stability theory of creep, by fitting the monitoring data on $7^{\text {th }}, 10^{\text {th }}, 16^{\text {th }}$ and $19^{\text {th }}$, the value of parameter $\xi, A, \alpha$ and $v_{0}$ can be obtained. Then the aging conjugate point $t_{\mathrm{p}}$ and the destabilization time $t_{\mathrm{f}}$ were calculated. Table 1 lists the obtained value of all parameters and the time $t_{\mathrm{p}}$ and $t_{\mathrm{f}}$. It was predicted that the destabilization time would be March $19^{\text {th }}$, which is not later than the time when the last monitoring data was got. Hence, it could not be regarded as the time that landslide would occur and no landslide warning was made. However, it was decided that the deformation should be monitored every day since the deformation rate increased dramatically.

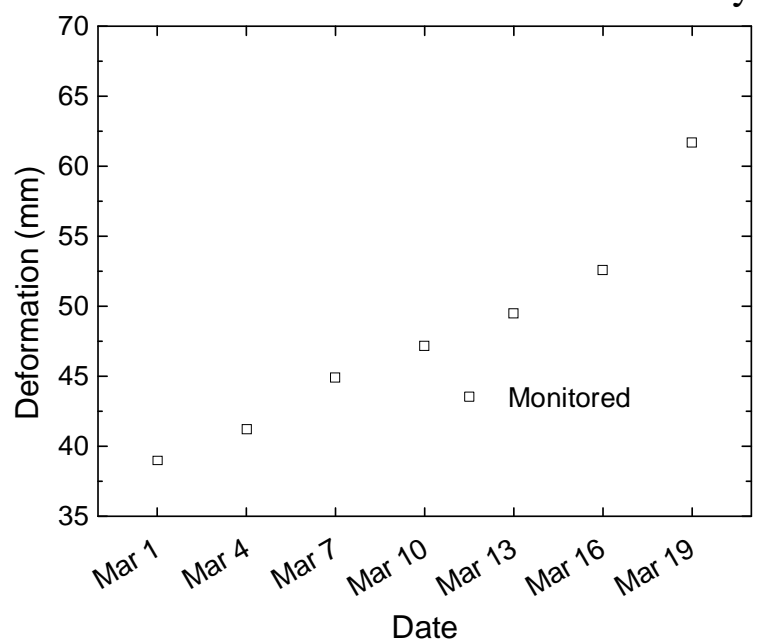

Fig. 2 Slope deformation at GPS-17 until $19^{\text {th }}$

Table 1 Predicted parameters using monitoring data on March $7^{\text {th }}, 10^{\text {th }}, 16^{\text {th }}$ and $19^{\text {th }}$

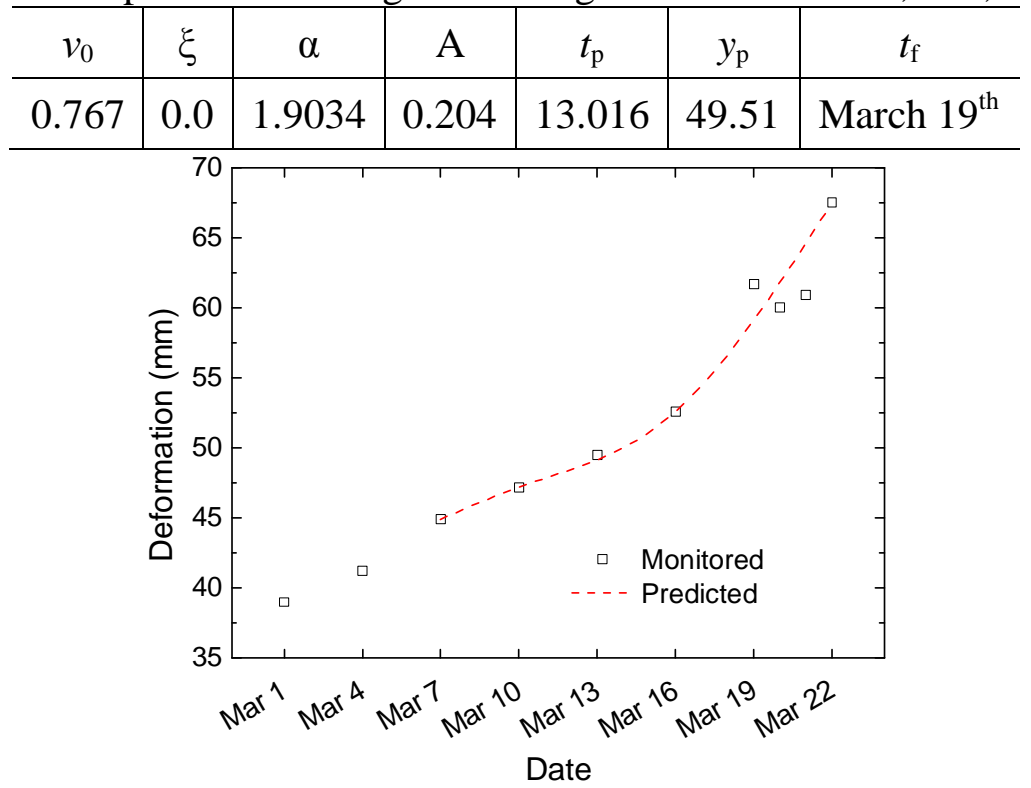

Fig. 3 Slope deformation at GPS-17 until $22^{\text {nd }}$

Fig. 3 shows the monitoring data from $1^{\text {st }}$ to $22^{\text {nd }}$ of the slope deformation at GPS- 17 site. By fitting the monitoring data on $7^{\text {th }}, 10^{\text {th }}, 16^{\text {th }}$ and $22^{\text {nd }}$ using the aging stability theory of creep, the aging conjugate point $t_{\mathrm{p}}$ and the destabilization time $t_{\mathrm{f}}$, as well as all parameters, were obtained and listed in Table 2. It was predicted the destabilization time $t_{\mathrm{f}}$ would be March $24^{\text {th }}$ and the predicted creep curve is displayed in Fig. 3. 
Table 2 Predicted parameters using monitoring data on March

\begin{tabular}{c|c|c|c|c|c|c|c}
\hline Data group & $v_{0}$ & $\xi$ & $\alpha$ & $\mathrm{A}$ & $t_{\mathrm{p}}$ & $y_{\mathrm{p}}$ & $t_{\mathrm{f}}$ \\
\hline $7^{\text {th }}, 10^{\text {th }}, 16^{\text {th }}$ and $22^{\text {nd }}$ & 0.767 & 0.0 & 1.837 & 0.121 & 11.969 & 48.71 & March $24^{\text {th }}$ \\
\hline $13^{\text {th }}, 16^{\text {th }}, 20^{\text {th }}$ & $/$ & $/$ & 1.839 & 0.122 & $/$ & $/$ & March $24^{\text {th }}$ \\
\hline $13^{\text {th }}, 16^{\text {th }}, 22^{\text {nd }}$ & $/$ & $/$ & 1.834 & 0.119 & $/$ & $/$ & March $24^{\text {th }}$ \\
\hline $13^{\text {th }}, 20^{\text {th }}, 22^{\text {nd }}$ & $/$ & $/$ & 1.827 & 0.114 & $/$ & $/$ & March $24^{\text {th }}$ \\
\hline $16^{\text {th }}, 20^{\text {th }}, 22^{\text {nd }}$ & $/$ & $/$ & 1.883 & 0.113 & $/$ & $/$ & March $24^{\text {th }}$ \\
\hline
\end{tabular}

Since the predicted $t_{\mathrm{f}}$ is later than March $22^{\text {nd }}$, it is probably the time when landslide would occur. Thus four more examinations were performed to determine the destabilization time $t_{\mathrm{f}}$ using Saito model expressed as Eq. 2 and the results are listed in Table 2. As listed in Table 2, all these examinations also showed March $24^{\text {th }}$ would be the destabilization time. Hence, the warning of landslide was made that the slope sliding would occur on March $24^{\text {th }}$.

In the morning of March $24^{\text {th }}$, the slope slide occurred around GPS-17 monitoring site. Since the constructors and equipment were evacuated from construction site ever since the landslide warning was made, there were no casualties and property damage caused by the slope slide.

\section{Conclusions}

The aging stability theory of creep employs the Kelvin model and Saito model to describe the steady-state and accelerated creep of rock or soil, respectively. This theory has been successfully used in the project of Mount Niu-shou tourist district to predict the destabilization time $t_{\mathrm{f}}$ of slope by fitting the monitoring data. The predicted destabilization time $t_{\mathrm{f}}$ is close to and earlier than the real time of landslide, which allows making landslide forecast in time and taking measures to reduce casualties and property loss.

\section{Acknowledgements}

This work was funded by the Excellent Technical Leader Program of Shanghai Municipal (NO.14XD1420400) and Excellent Youth Foundation of Xian Dai Architectural Design Co., Ltd. (NO.14-I-0015-JI).

\section{References}

[1] M. Saito. Forecasting time of slope failure by tertiary creep. Journal of Japan Landslide Society Vol. 4 (1968), p. 1-8.

[2] B. Voight. A method for prediction of volcanic eruptions. Nature Vol. 332 (1988), p. 125-130.

[3] X.H. He, S.J. Wang, R. H. Xiao, X.Y. Rao and B. Luo. Improvement and application of synergetic forecast model for landslides. Chinese Journal of Geotechnical Engineering Vol. 35 (2013), p. 1839-1848.

[4] W. Thompson. On the elasticity and viscosity of metals. Proceedings of the Royal Society of London Vol. A14 (1865), p. 289-297.

[5] R.G. Yang. Structure stability theory of geomaterial and forecast of landslide, Geological Press, Beijing 2010 